\title{
SISTEM PAKAR MENENTUKAN KEAHLIAN SISWA MENGGUNAKAN METODE FORWARD CHAINING
}

\author{
Librian Yudhista Prambudi, Achmad Zakki Falani \\ Universitas Narotama Surabaya Jawa Timur, Indonesia \\ Email: librianyudhistap@fik.narotama.ac.id,achmad.zakki@narotama.ac.id
}

\begin{abstract}
Abstrak
SMK Negeri 5 Surabaya termasuk salah satu SMK unggulan di Surabaya yang menghasilkan alumni yang siap kerja. Pemilihan kompetensi keahlian di SMK Negeri 5 Surabaya cenderung subjektif, karena adanya dorongan orang tua dan teman yang menyarankan masuk kompetensi keahlian tertentu, sehingga siswa merasa salah masuk kompetensi keahlian tersebut. Pada SMK Negeri 5 Surabaya tidak ada tes khusus untuk menentukan kompetensi keahlian apa yang cocok dengan siswa tersebut, dari hasil observasi dan wawancara yang telah dilakukan penulis yang mendasari penelitian ini untuk dibuatnya sebuah aplikasi Sistem Pakar berbasis web menggunakan framework Laravel dan menggunakan parameter berdasarkan hasil rapor dan kriteria ketuntasan minimal pada kelas X sebagai acuan dasar dengan tujuan untuk mempermudah para siswa siswi dalam memberikan second opinion terhadap kompetensi keahlian yang dimiliki para siswa. Metode yang digunakan dalam pembuatan Sistem Pakar ini adalah menggunakan metode Forward Chaining, metode yang memberikan rule based dari inferensi yang melakukan penalaran berdasarkan suatu masalah dan akan menyimpulkan suatu solusi. Serangkaian proses telah dilewati penulis mulai dari pengumpulan data dengan cara observas, dan wawancara, perancangan sistem, implementasi, dan pembuatan aplikasi terciptalah sebuah aplikasi Sistem Pakar ini dapat mengatasi keluhan siswa yang tidak bisa mengikuti pembelajaran karena kurangnya minat belajar karena tidak sesuai dengan yang diinginkan.
\end{abstract}

Kata Kunci: Forward Chaining; Sistem Pakar; Rule-based; Kompetensi Keahlian

\section{Abstract}

SMK Negeri 5 Surabaya is one of the flagship vocational schools in Surabaya that produces alumni who are ready to work. The selection of expertise competencies in SMK Negeri 5 Surabaya tends to be subjective, because of the encouragement of parents and friends who suggest entering certain skill competencies, so students feel wrong in the competence of those skills. At SMK Negeri 5 Surabaya there is no specific test to determine what competence of expertise is suitable for the student, from the results of observations and interviews that have been conducted by the author of this study to create a web-based Expert System application using the Laravel framework and use parameters based on report card results and minimum completion criteria in class $X$ as a basic reference with the aim to facilitate students in providing second opinion. the competence of the students. The method used in the creation of this Expert System is to use the Forward Chaining method, a method

$\begin{array}{ll}\text { How to cite: } & \text { Prambudi, L., Falani, A, Z., (2022) Sistem Pakar Menentukan Keahlian Siswa Menggunakan Metode } \\ & \text { Forward Chaining, Syntax Idea, 4(1), https://doi.org/10.36418/syntax-idea.v4i1.1711 } \\ \text { E-ISSN: } & \text { 2684-883X } \\ \text { Published by: } & \text { Ridwan Institute }\end{array}$


that provides a rule based on inference that performs reasoning based on a problem and will conclude a solution. A series of processes have been passed by the author ranging from data collection by observing, and interviews, system design, implementation, and application creation created an application this Expert System can overcome the complaints of students who can not follow learning because of lack of interest in learning because it is not in accordance with the desired.

Keywords: Forward Chaining; Expert System; Rule-based; Expertise Competency

\section{Received: 2021-12-22; Accepted: 2022-01-05; Published: 2022-01-20}

\section{Pendahuluan}

Sekolah Menengah Kejuruan Negeri (SMKN) 5 Surabaya adalah sebuah lembaga instansi Negara yang bergerak di bidang pendidikan dengan luas lahan 5,3 hektar atau $53,113 \mathrm{~m}^{2}$, di lahan yang luas tersebut terdapat 8 kompetensi keahlian. SMK Negeri 5 Surabaya termasuk salah satu SMK unggulan di Surabaya yang menghasilkan alumni siap kerja, pemilihan kompetensi keahlian di SMK Negeri 5 Surabaya cenderung secara subjektif, karena adanya dorongan orang tua dan teman yang menyarankan masuk kompetensi keahlian tertentu, sehingga siswa merasa salah masuk kompetensi keahlian tersebut.

Tujuan dari pendidikan yaitu untuk menciptakan seseorang yang berkualitas dan berkarakter sehingga memiliki pandangan yang luas untuk menciptakan suatu cita-cita yang diharapkan dan mampu beradaptasi secara cepat dan tepat di dalam berbagai lingkungan. Karena pendidikan merupakan suatu hal yang sangat penting bagi seorang manusia, dengan perkembangan dunia saat ini menuntut setiap orang untuk memiliki pendidikan setinggi mungkin. kemudahan dalam segala aktivitas maupun pekerjaan menjadi hal yang sangat diinginkan oleh manusia. Tanpa pendidikan yang baik, maka sulit untuk mendapatkan segala kemudahan tersebut.

Sistem Pakar atau bisa di sebut dengan Expert System adalah sistem informasi yang berisi pengetahuan sesorang pakar (Fadel, Mardayulis, and Yunita 2019),(Salisah, Lidya, and Defit 2015) sehingga dapat digunakan untuk konsultasi. Sistem Pakar merupakan pengembangan kecerdasan buatan atau disebut juga dengan Artificial Intelligence (AI) yang menggabungkan pengetahuan dan penelusuran data untuk memecahkan masalah yang secara normal memerlukan keahlian manusia (Mulyani, Hidayat, and Ulfa 2021).

Dari hasil observasi di lapangan banyaknya permasalahan tentang ketidakcocokan kompetensi keahlian yang dipilih oleh siswa, maka metode Forward Chaining (Coles et al. 2010) (Al-Ajlan 2015) merupakan metode yang cocok untuk permasalahan ini karena permasalahan ini membutuhkan menelusuri data dan aturan agar mencapai tujuan yang di inginkan.

Berikut ini beberapa penelitian terdahulu yang telah dilakukan oleh peneliti lain diantaranya yaitu berjudul "Sistem Pakar Pusat Informasi Konseling Remaja dengan Metode Backward Cahining", penelitian pada tahun 2018 yang bertujuan agar lebih 
efektifnya suatu proses konseling dalam penanganan masalah-masalah siswa dan siswi SMAN 2 Dumai dan menjadikan penerapan pendidikan berbasis karakter yang tepat sasaran. (Fadel et al. 2019). Penelitian selanjutnya berjudul "Sistem Pakar Untuk menentukan Jurusan Kuliah Berdasarkan Minat dan Bakat Siswa SMA dengan Metode Forward Chaining", penelitian pada tahun 2018 yang bertujuan dengan adanya sistem pakar untuk menentukan jurusan berdasarkan minat dan bakat ini dapat membantu siswa dalam menentukasn pilihan jurusannya dan mengeahui kecerdasan yang dimiliki tanpa harus bertemu langsungan psikologi. Penelitian selanjutnya berjudul "Sistem Pakar Untuk Menentukan Bakat Anak Berdasarkan Kepribadian Menggunakan Metode Forward Chaining”. Penelitian pada tahun 2017 yang bertujuan untukk menentukan bakat pada anak sesuai dengan kepribadian menggunakan model Forward Chaining (Lestari and Handayani 2017). Penelitian selanjutnya "Sistem Pendukung Keputusan Untuk Memilih Ekstrakulikuler Siswa di SDN Kaliasin VI-285 Surabaya dengan Menggunakan Metode Rule Based System", dapat membantu memberikan rekomendasi kegiatan ekstrakurikuler sehinga mengatasi permasalahan pemilihan kegiatan ekstrakurikuler serta dapat mempermudah siswa dalam memilih kegiatan ekstrakurikuler (Lestari and Handayani 2017) (Zainul Efendy dan Azizel Wanjas Saputra Genda 2018) (Munthafa and Mubarok 2017).

\section{Metode Penelitian}

Flowchart atau bagan alir merupakan tahapan-tahapan yang dilakukan dalam menyelesaikan penelitian sehingga dapat mempermudah pembaca dalam memahami alur penelitian tersebut. Adapaun flowchart kerja penelitian dapat dilihat pada gambar 1 . Flowchart kerja penelitian.

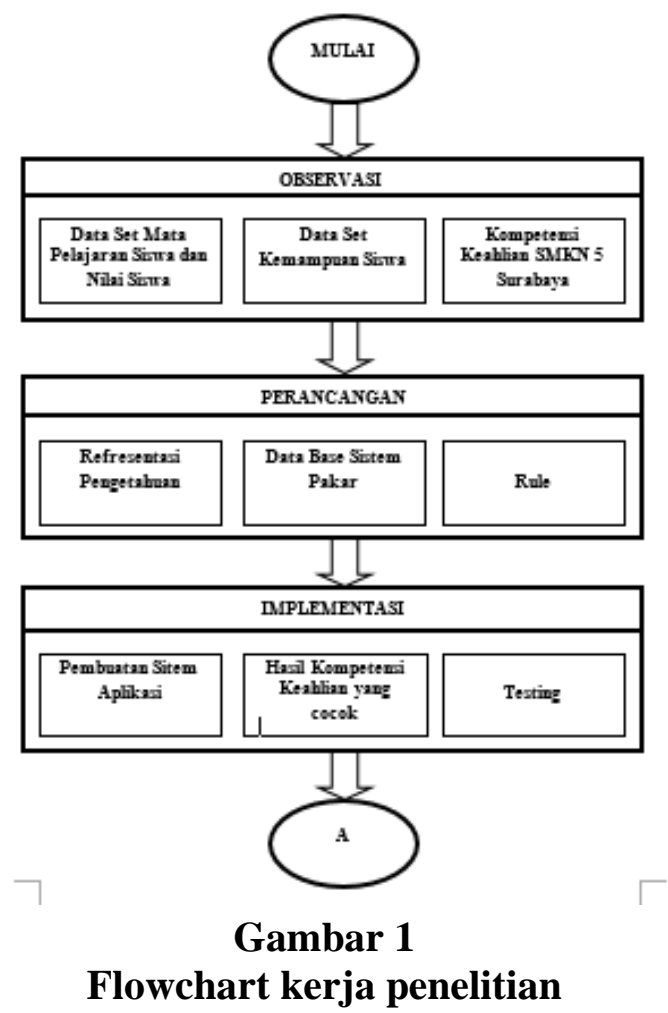

Syntax Idea, Vol. 4, No. 1, Januari 2022 
Gambar 1. Flowchart kerja penelitian ini menjelaskan alur penelitian untuk penentuan kompetensi keahlian siswa di SMK Negeri 5 Surabaya dengan mengadopsi modeling dari Sistem Pakar dengan metode Forward Chaining, adapun harapan dari penulis yang dapat dicapai dari penelitian ini. Berikut deskripsi tahapan-tahapan di atas yaitu:

1. Pengumpulan Data Analisis / Observasi (Purnomo 2011)

Pada tahap pengumpulan data analisis atau observasi penulis melakukan wawancara bersama dengan guru-guru dan siswa, kemudian dilanjutkan dengan melakukan pengumpulan data yang bersumber dari nilai rapor siswa kelas $\mathrm{X}$, diperoleh dari aplikasi sekolah berupa E-rapor, adapun data yang diperoleh memiliki beberapa indikator parameter seperti nilai minimum untuk yang cocok sehingga dapat cocok di kompetensi keahlian tersebut atau bisa disebut dengan kreteria ketuntasan minimal (KKM) (Fachriza and Purwani 2020). Berikut adalah dataset mata pelajaran dan kompetensi keahlian yang ada di SMK Negeri 5 Surabaya.

2. Perancangan (Sihotang 2019)

a) Proses Pengolahan Kategori

Pada proses ini hanya administrator yang mempunyai hak melakukan pengaturan data nilai rapor yang akan dijadikan tindakan pada Sistem Pakar. Data kategori penilaian tersebut akan di masukan pada inputan proses bentuk pelanggaran Sistem Pakar.

b) Proses Pengolahan inputan

Proses pengolahan inputan ini merupakan proses dari bentuk nilai dan keahlian seorang siswa yang diperoleh siswa itu sendiri, kemudian akan diinputkan kedalam sistem.

c) Proses Pengolahan Keputusan

Pada proses pengolahan keputusan merupakan jawaban dari hasil relasi nilai siswa dengan keahlian siswa yang telah di inputkan kedalan proses tahap kedua oleh guru bimbingan konseling.

3. Implementasi

Tahapan implementasi sistem bertujuan untuk mengetahui sejauh mana program yang dibuat bisa bekerja untuk merekomendasikan atau memberikan suatu pilihan kompetensi keahlian untuk siswa dengan metode Forward Chaining. Di tahapan ini juga penulis melakukan uji testing demi mendapatkan akurasi program yang dibangun.

Dari tahapan observasi didapatkan beberapa data untuk bahan penelitian berikut. Dibawah ini merupakan data-data yang diperlukan: 
Tabel 1

Daftar Kompetensi Keahlian

\begin{tabular}{ll}
\hline Kode & Kompetensi Keahlian \\
\hline TL01 & $\begin{array}{l}\text { Teknik Konstruksi Gedung, Sanitasi dan } \\
\text { Perawatan (KGSP) }\end{array}$ \\
\hline TL02 & $\begin{array}{l}\text { Teknik Elektronika Daya dan Komunikasi } \\
\text { (TEDK) }\end{array}$ \\
\hline TL03 & Teknik Tenaga Listrik (TTL) \\
\hline TL04 & $\begin{array}{l}\text { Teknik Fabrikasi Logam dan Manufaktur } \\
\text { (TFLM) }\end{array}$ \\
\hline TL05 & $\begin{array}{l}\text { Teknik dan Manajemen Perawatan Otomotif } \\
\text { (TMPO) }\end{array}$ \\
\hline TL06 & Teknik Alat Berat (TAB) \\
\hline TL 07 & Teknik Kimia Analis (KA) \\
\hline TL08 & Teknik Kimia Industri (KI) \\
\hline TL 09 & $\begin{array}{l}\text { Jurusan di SMK Negeri 5 tidak ada yang } \\
\text { cocok untuk anda. Coba di sekolah lain }\end{array}$ \\
\hline
\end{tabular}

Tabel 2

Mata Pelajaran Umum

\begin{tabular}{ll}
\hline Kode & Mata Pelajaran \\
\hline P01 & Pendidikan Agama dan Budi Pekerti \\
\hline P02 & Pendidikan Pancasila dan Kewarganegaraan \\
\hline P03 & Bahasa Indonesia \\
\hline P04 & Matematika \\
\hline P05 & Sejarah Indonesia \\
\hline P06 & Bahasa Inggris \\
\hline P07 & Seni Budaya \\
\hline P08 & Prakarya dan Kewirausahaan \\
\hline P09 & Kimia \\
\hline P10 & Fisika \\
\hline P11 & Simulasi Digital \\
\hline
\end{tabular}

Tabel 3

Mata Pelajaran Kompetensi

\begin{tabular}{ll}
\hline Kode & Mata Pelajaran \\
\hline P12 & C1 \\
\hline P13 & C2 \\
\hline P14 & C3 \\
\hline
\end{tabular}




\section{Tabel 4}

Nilai Siswa

\begin{tabular}{ll}
\hline Kode & Nilai Siswa \\
\hline PX01 & $\mathrm{X}<50$ nilai dibawah 50 \\
\hline PX02 & $50<=\mathrm{X}<=60$ nilai di antara $50-60$ \\
\hline PX03 & $60<=\mathrm{X}<=60$ nilai di antara $60-75$ \\
\hline PX04 & $75<=\mathrm{X}<=60$ nilai di antara $75-85$ \\
\hline PX05 & $85<=\mathrm{X}<=60$ nilai di antara $85-95$ \\
\hline
\end{tabular}

Berdasarkan data yang diberikan dan beberapa pengetahuan pakar dari seorang guru menghasilkan rules(Khosyi'Ah et al. 2018) seperti dibawah ini :

Tabel 5

Contoh Rules

\begin{tabular}{lll}
\hline Rule & IF & Then \\
\hline 1 & P04=PX04, P11=PX05, P10=PX02 & TL01 \\
\hline 2 & P04=PX05, P06=PX05, & TL07 \\
& P09=PX04, P10=PX02 & \\
\hline
\end{tabular}

Pada tabel 5 diatas adalah sampel contoh dari rules yang digunakan, tahap pertama kita cocokan terlebih dahulu siswa dengan kompetensi keahlian yang sudah di pilihnya dengan membandingkan nilai kompetensi dari C1, C2, C3 dengan nilai KKM di kompetensi keahlian yang di pilih jika criteria tidak memungkinkan maka nilai pelajaran umum siswa akan di bandingkan dengan KKM setiap kompetensi di SMK Negeri 5 Surabaya dan menghasilkan poin, dari poin yang terbanyak akan menjadi kompetensi yang diusulakan oleh program.

4. Pembuatan Aplikasi Program

a. Proses Pengolahan Kategori

Pada proses ini hanya administrator yang mempunyai hak akses yang dapat melakukan pengaturan data nilai rapor yang akan di jadikan tindakan pada Sistem Pakar. Dari data kategoru tersebut akan di masukan pada inputan sistem sebuah proses bentuk pelanggaran Sistem Pakar.

b. Proses Pengolahan Inputan

Merupakan inputan dari bentuk nilai dan keahlian siswa di inputkan oleh siswa itu sendiri.

c. Proses Pengolahan Keputusan

Pada proses pengolahan keputusan merupakan jawaban dari hasil relasi nilai siswa dengan keahlian siswa yang di inputkan oleh guru bimbingan konseling. 


\section{Hasil dan Pembahasan}

\section{Analisis Kebutuhan}

Dari hasil pengamatan yang dilakukan dengan cara wawancara sampai observasi, penulis dapat menggambarkan bahwasanya siswa di SMK Negeri 5 Surabaya masih belum mengetahui bakat yang mereka miliki sendiri, sehingga para siswa masih bingung untuk memilih kompetensi keahliannya sendiri berdasarkan minat dan bakat yang mereka punya.

1) Desain Sistem Unified Modeling Language (UML)

\section{- Usecase Diagaram}

Diagaram usecase digunakan untuk mengetahui alur fungsi apa saja yang berhak menggunakan fungsi-fungsi tersebut. Yang ditekankan pada diagram ini adalah "apa" proses yang akan dilakukan dari sistem, dan bukan "bagaimana". Usecase diagram dapat dilihat gambar 2 dibawah ini.

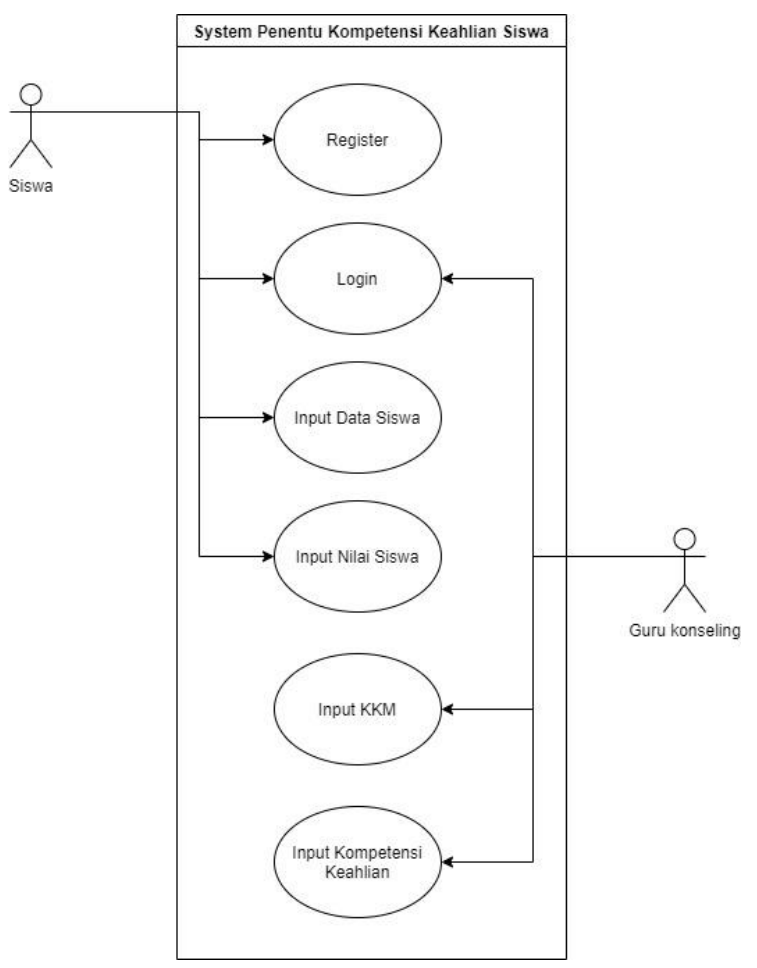

\section{Gambar 2 \\ Usecase Diagaram Penentu Kompetensi Keahlian Siswa}

Berdasarkan Gambar 2 diatas menjelaskan mengenai alur dari seorang user yakni user siswa, dan admin sebagai guru terhadap sistem penentu. Dimana siswa diharuskan melakukan register atau login terlebih dahulu, sebelum melakukan proses input data siswa setelah itu baru dapat mengisi nilai rapor tersebut kedalam sistem, kemudian guru langkah pertama adalah login menggunakan username dan password yang sudah terregister dan bisa mengakses input KKM dan input kompetensi keahlian siswa. 
- Class Diagaram

Class diagram yang dibuat penelitian ini terdiri dari 6 class. Permodelan class diagram pada suatu sistem dapat memberikan gambaran hubungan antara class dari suatu sistem, juga memberikan penjelasan aturan dan tanggung class. Pada gambar 3 menggambarkan struktur class diagram kompetensi keahlian siswa.

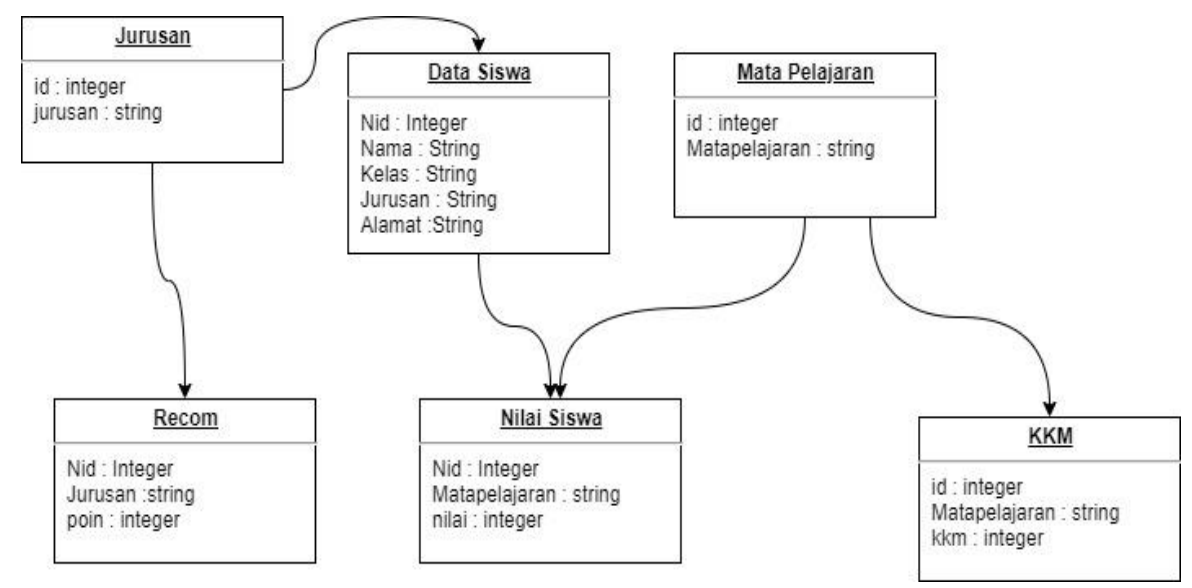

Gambar 3

Class Diagram Penentu Kompetensi Keahlian Siswa

Pada gambar 3 diatas menunjukan bahwa class-class yang ada pada sistem penentu kompetensi keahlian siswa yang terdiri dari class data siswa, jurusan, mata pelajaran, kkm, dan recom saling terhubung satu sama lainnya.

1) Implementasi

Aplikasi penentu kompetensi keahlian siswa terdiri dari halaman register, halaman login, halaman input data siswa, halaman input nilai rapor siswa, halaman input $\mathrm{kkm}$ mata pelajaran, halaman input mata pelajaran, dan halaman rekomendasi. Siswa diharuskan mempunyai akun terlebih dahulu agar bisa memasukkan data siswa dan nilai rapor siswa. dibawah ini contoh dari beberapa hasil dari implementasi sistem yang telah dibangun.

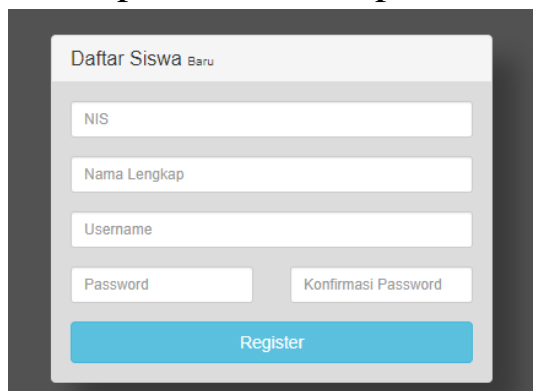

Gambar 4 Halaman register

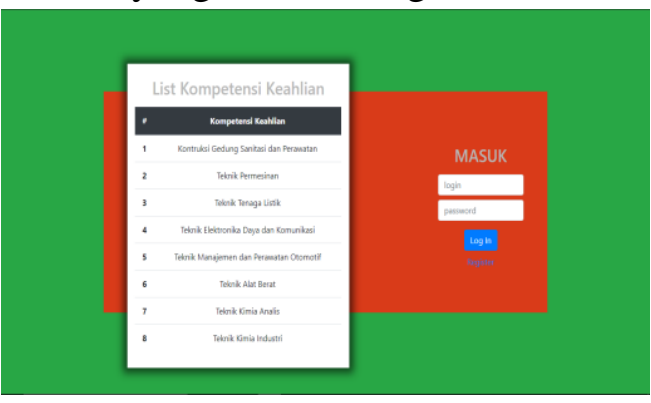

Gambar 5 Halaman login 
2) Pengujian

Pengujian yang dilakukan oleh sistem ini menggunakan black box dan sedikit white box testing. Hasil pengujian dapat di lihat dibawah ini form validasi.
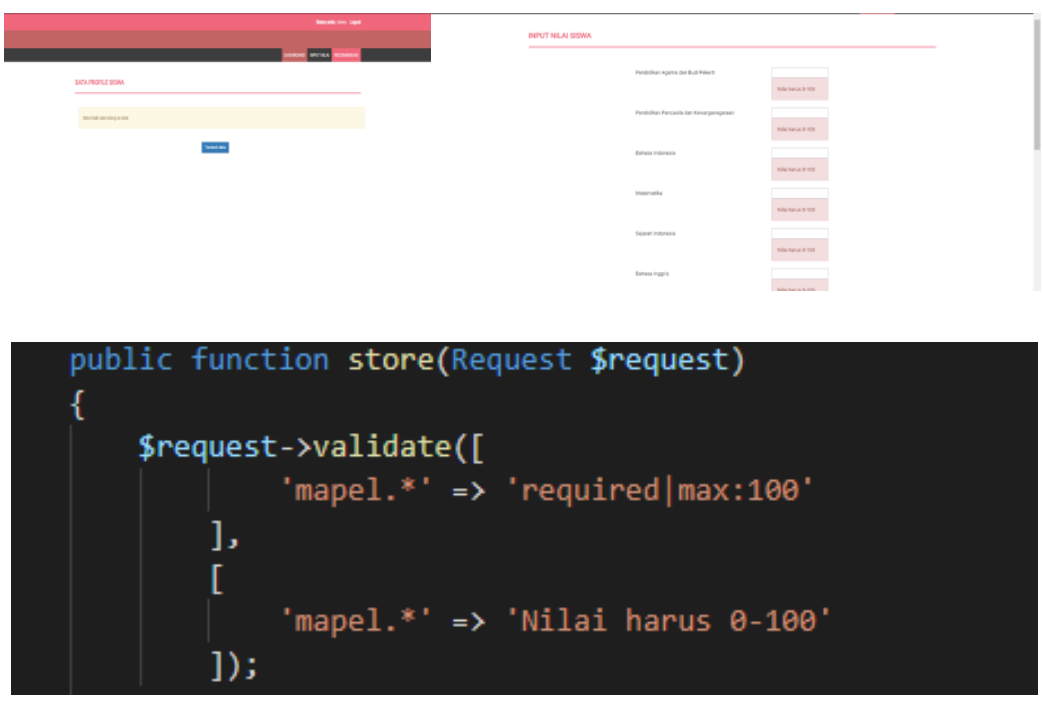

\section{Gambar 6 \\ Validasi form}

Seperti gambar 6 dimana input tidak boleh null dan nilai harus $0-100$ dan jika siswa belum mengisi data siswa dan nilai rapor siswa tidak akan melihat pesan jika data belum di input.

3) Validasi

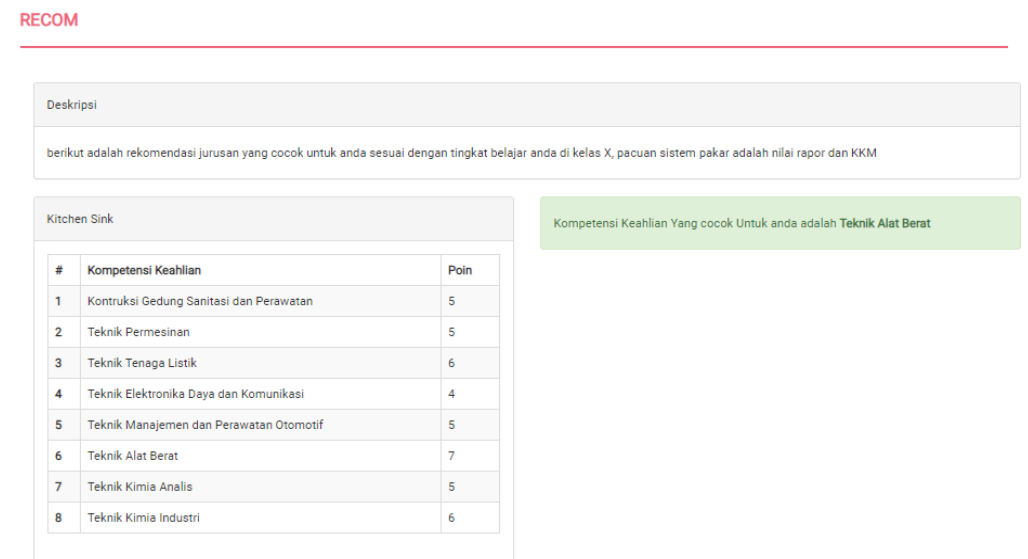

Gambar 7

Rekomendasi

Pada gambar 7 ouput berupa list kompetensi keahlian dan point setiap kompetensi keahlian, point tertinggi di ambil untuk rekomendasi jurusan yang paling mendekati atau cocok bagi siswa tersebut. 


\section{Kesimpulan}

Berdasarkan dari penelitian ini yang sudah dikerjakan mulai dari tahap pengambilan data, berupa data nilai kemampuan siswa berdasarkan mata pelajaran yang diambil sehingga kita dapat mengolahnya menjadi sebuah informasi yang sangat berguna atau memberikan suatu insight terhadap stakeholder. Output dari penelitian ini yakni sebuah aplikasi berbasis web untuk menentukan kompetensi keahlian yang telah mendapatkan inputan dari guru berdasarkan nilai yang diperoleh siswa dalam proses belajar mengajar. Aplikasi tersebut di harapkan dapat digunakan oleh siswa di koordinir oleh guru dalam melakukan bimbingan jika siswa merasa tidak cocok dengan kompetensi keahlian yang di pilihnya, dengan fitur siswa dapat melihat poin berapa saja yang dia dapat di kompetensi keahlian lainya yang ada di SMK Negeri 5 Surabaya, sehingga dapat memberikan suatu second opinion dalam pengambilan keputusan dalam menentukan minat dan bakat seorang siswa, sehingga siswa tidak perlu merasa bingung lagi terhadap bakat yang dimiliki setiap siswa. Saran untuk penelitian selanjutnya diharapkan bisa lebih berkembangan lagi dengan metode metode yang terbaru dan dapat memberikan suatu informasi atau gambaran kepada siswa yang cocok dengan minat bakat dalam menentukan mau melanjutkan ke perguruan tinggi atau lebih condong dalam dunia industri kerja.

\section{BIBLIOGRAFI}

Al-Ajlan, Ajlan. 2015. "The Comparison between Forward and Backward Chaining." International Journal of Machine Learning and Computing 5(2):106-13. Google Scholar

Coles, Amanda, Andrew Coles, Maria Fox, and Derek Long. 2010. "Forward-Chaining Partial-Order Planning." ICAPS 2010 - Proceedings of the 20th International Conference on Automated Planning and Scheduling (Icaps):42-49. Google Scholar

Fachriza, Muhammad, and Fenny Purwani. 2020. "Penentuan Konsentrasi Pembagian Keahlian Siswa Untuk Menjadi Developer Menggunakan Metode Forward Chaining ( Studi Kasus : Synapse Academy ).” 3(1):177-84. Google Scholar

Fadel, Ahmad, Mardayulis Mardayulis, and Putri Yunita. 2019. “Aplikasi Sistem Pakar Pusat Informasi Konseling Remaja (Pik-R) Di Sman 2 Dumai Dengan Metode Backward Chaining Menggunakan Bahasa Pemograman Php." I N F O R M a T I $K A$ 10(2):47. Google Scholar

Gunawan, Paramitha, Geraldo Julius Halim, Kenneth Liem Hardadi, Stanley Tejadinata, and Simon Prananta Barus. n.d. "Aplikasi Sistem Pakar Berbasis Web Untuk Mendeteksi Ras Kecoa Dengan Metode Forward Chaining.” 6(2):118-23. 
Khosyi'Ah, S., M. Irfan, D. S. Maylawati, and O. S. Mukhlas. 2018. "Analysis of Rules for Islamic Inheritance Law in Indonesia Using Hybrid Rule Based Learning." IOP Conference Series: Materials Science and Engineering 288(1). Google Scholar

Lestari, S., and R. Handayani. 2017. "Sistem Pakar Untuk Menentukan Bakat Anak Berdasarkan Kepribadian Menggunakan Model Forward Chaining." Bina Insani ICT Journal 4(1):47-56. Google Scholar

Mulyani, Evi Dewi Sri, Cepi Rahmat Hidayat, and Tammy Chintya Ulfa. 2021. "Sistem Pakar Untuk Menentukan Jurusan Kuliah Berdasarkan Minat Dan Bakat Siswa SMA Dengan Menggunakan Metode Forward Chaining." CSRID (Computer Science Research and Its Development Journal) 10(2):80. Google Scholar

Munthafa, Agnia Eva, and Husni Mubarok. 2017. "Penerapan Metode Analytical Hierarchy Process Dalam Sistem.” Jurnal Siliwangi 3(2):192-201. Google Scholar

Pratama, I. Putu Agus Eka. 2021. "Design and Implementation of an Artificial Intelligence-Based Heart Disease Diagnosis System." Indonesian Journal of Engineering and Science 3(1):033-040. Google Scholar

Purnomo, Bambang Hari. 2011. "Pendahuluan Kedudukan Observasi Dalam Tahapan PTK Metode Observasi." Metode Dan Teknik Pengumpulan Data Dalam Penelitian Tindakan Kelas (Classroom Action Research) 8:251-56. Google Scholar

Salisah, Febi Nur, Leony Lidya, and Sarjon Defit. 2015. "Sistem Pakar Penentuan Bakat Anak Dengan Menggunakan Metode Forward Chaining." Jurnal Ilmiah Rekayasa Dan Manajemen Sistem Informasi 1(1):62-66. Google Scholar

Sihotang, Hengki Tamando. 2019. "Sistem Pakar Untuk Mendiagnosa Penyakit Pada Tanaman Jagung Dengan Metode Bayes.” 3(1). Google Scholar

Zainul Efendy dan Azizel Wanjas Saputra Genda. 2018. "Indonesian Journal of Computer Science.” STMIK Indonesia Padang 6(1):62. Google Scholar

\section{Copyright holder:}

Librian Yudhista Prambudi, Achmad Zakki Falani (2022)

First publication right:

Syntax Idea

This article is licensed under:

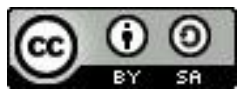

